\title{
The Research on Materials and Technique of "The lion rolling ball” parcel cloth of Qing Dynasty
}

\author{
Xueling Ren ${ }^{a}$, Shaobo Wang \\ Qingdao University Fine Art College, Qingdao, Shandong, China
}

\begin{abstract}
By studying on the little cotton textures from relics excavation, there is not a clear answer to when the China cotton planting started. Although Qiru area was the north weaving center, there were not so much unearthed fabrics. "The lion rolling ball" parcel cloth of Qing Dynasty is one of the seldom printed cottons. It contains rich culture, life custom and the information of weaving technology with cotton in the Qilu region. From the view of history, this paper analyzes the pattern model, fiber material, weaving technology of "The lion rolling ball" parcel cloth of Qing Dynasty. By comparing it with modern Lu brocade using empirical analysis method, we found that the yarns in fabric is cotton, one of ancient Asia cottons, which showed"The lion rolling ball" parcel cloth of Qing Dynasty played an important role in the history of cotton clothes.
\end{abstract}

\section{Introduction}

In history, there is no clear answer to when the cotton was originate and introduced. But it is confirmed that the cotton products were considered treasure at the central plain area of China from 6th century to 12th century, and they were used only by the ruling class[1]. The cottons planted in Qiru area were Asia cotton[3] introduced from China south at the end of Song Dynasty and the earlier of Yuan dynasty[2].

Qiru area has been an important weaving center since ancient times. Zhoucun, as the "Land wharf" of ancient silk, was ever the biggest place of silk and textile, dyeing and sales in north China; Changyi of Weifang was the famous hometown of silk, well-known city in history. The silk produced inLiutuan of Changyi was exported regularly, then Liutuan's silk craft was certified as the non-material cultural heritage. Zhoucun and Changyi, as the important silk cities, laid a strong foundation for the growth of textile printing and dyeing in Qiru area[4].

Because cotton clothes were used by the poor in old time, and the weather in Shandong was not suitable to keep the cotton fabrics, cotton texture was seldom remained. So "The lion rolling ball" parcel cloth of Qing Dynasty is also very rare to us.

By analyzing the fiber material, pattern model of "The lion rolling ball" parcel cloth of Qing Dynasty, this paper studies its historical value, material characteristics and the relationship with the modern cotton texture.

\section{The profile of "The lion rolling ball" parcel cloth of Qing Dynasty}

After looking up lots of documents and spot investigations, we learnt that the ancient cotton parcels were kept in some folk weaving artisans. Between 2006 2009 years, the author went to Changyi to do field investigation to search for the ancient cotton textures, and study the weaving skeleton and advanced dyeing culture.

During the investigation at Changyi in Feb. 2002, we succeeded in finding the aged women, Che xiuyun, who was born 8th years of the Republic of China. She is fromLiutuan county of Changyi City, and comes from one famous weaving family. Che xiuyun gave "The lion rolling ball" parcel cloth of Qing Dynasty, which she inherited from her mother, to us for further studying.

\subsection{The brief of "The lion rolling ball" parcel cloth of Qing Dynasty}

The pattern structure of "The lion rolling ball" parcel cloth of Qing Dynasty is axisymmetric, printed finely, and weaved delicately. It is the precious material for studying cotton fabrics of Qing Dynasty, and is also the typical specimens for studying cotton printing and dyeing technolgy.

According to Che xiuyun's memory, we know that this parcel is past to her through generations, and it is at least 300 years old up to now. It date bact about at the earler of 18 centry(Fig.1).

\subsection{Background}

\footnotetext{
a Corresponding author :rxlz999@163.com
} 


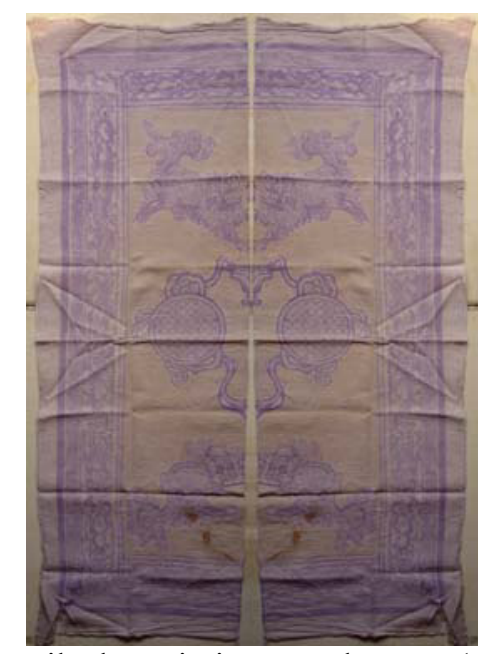

Fig. 1 cotton textile dye printing parcel pattern(collection of the author)

Only half of this parcel is left, and $36 \mathrm{~cm}$ width, $106 \mathrm{~cm}$ length. So the complete parcel should be $71 \mathrm{~cm} \mathrm{X}$ $106 \mathrm{~cm}(1 \mathrm{~cm}$ seam $)$. The parcel was weaved manually, single-color printed. Although it is a little soiled and broken, the condition is good. It is white cloth, purple printed(faded blue), and the pattern is clear.

\section{Analysis of "The Lion Rolling Ball" Parcel Of Qing Dynasty}

\subsection{Analysis of the parcel pattern}

( 1 ) "The lion rolling ball": Parcel pronounces "Baofu" in Chinese, which means good fortune, and people living in Qiru area think that the bigger the parcel is, the more fortune will get. This also implicits good wishes to daughter from her family. So the selected patterns always pose auspicious messages. For examples, "phoenix passing through peony" implicts beauty, brightness, happiness and richness(Fig. 2), "Carps Jumping over the Dragon Gate" implicts social climbing and good luck, " bursting Pomegranate" implicts more descendants, and more blessedness(Fig. 3), " lion rolling silk ball" means that lions send auspiciousness, and " two lions rolling silk ball" symbolizes the human reproductive ceremony[5].

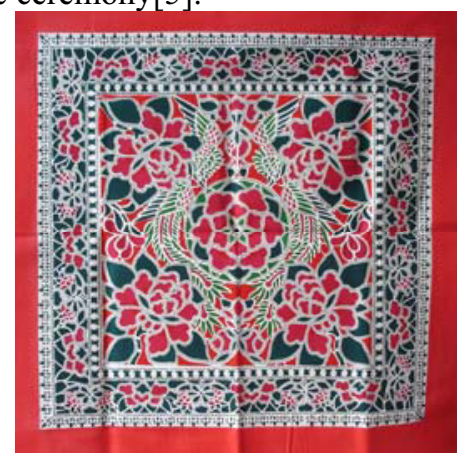

Fig. 2 phoenix passing through peony

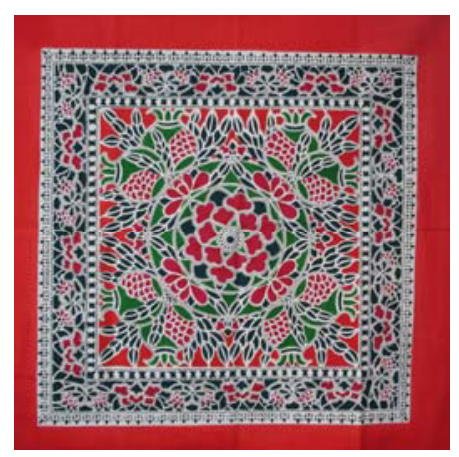

Fig. 3 bursting Pomegranate

(Original author: Zhang mingjian, folk artisan, famous inheritance man of China folk culture. Collected by the author of this paper )

(2) Characteristics of pattern: The pattern of "The lion rolling ball" parcel cloth of Qing Dynasty is full of luck message(Fig. 1). Based on the central axis, pattern is symmetrical on two sides. Two lions with different shapes and a pair of rolled silk balls compose of the main dermatoglyphic pattern. From inner to outside are the two-continual ribbon flower made up of inner edges, auspicious cloud, fret pattern and outer edges in turn. "The lion rolling ball" is one symbol of human reproductive ceremony in folk. The decorated auspicious cloud on lions symbolizes auspicious wishes, the repeated copper cash patterns inside the rolled silk ball means profits pouring in from all sides, and the surrounding lucky cloud pattern expresses tranquil and happy. The fret patterns are geometrical veins which are derived from thunder veins on pottery and bronze and their continuos distribution means successive rich. The complete pattern symbolizes auspiciousness and affluence[6].

In the selection of topic, "The lion rolling ball" parcel of Qing Dynasty is in accordance with the modern "The lion rolling ball" parcel. But they are a little difference in technique of expression. The main veins of "The lion rolling ball" Qing Dynasty are representational, the line style is elegant and smooth, and the atmosphere of picture is vivid; In other side, the main veins of modern JiNing color printed "The lion rolling ball" parcel are more patterning, the line style is standardized. The atomospher of picture is passinated with some solemnity.

\section{2 material analysis of the cotton fiber}

According to Che xiuyun's description, “The lion rolling ball" parcel cloth of Qing Dynasty is pure cotton with flat grain, printed in blue pattern. We tested the yarn diameter and size under DXS-19A microscope. The pictures under digital 3D video fiber measure system-HZ SCOPE are following. (Fig. 4, Fig. 5) 


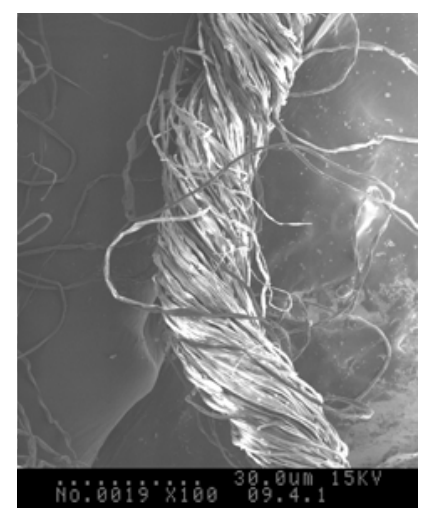

Fig. 4 100X cotton parcel yarn of Qing Daynasty

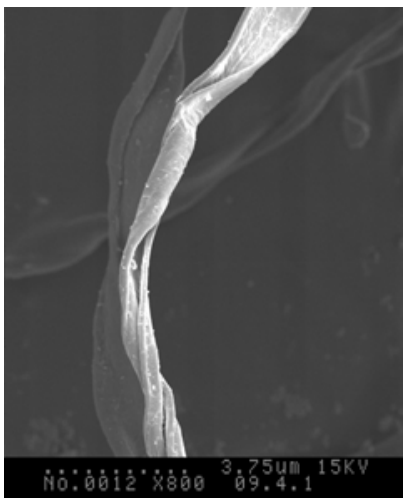

Fig. 5 800X cotton parcel yarn of Qing Daynasty( by DXS-10A electronic microscope)

"The lion rolling ball" parcel cloth of Qing Dynasty was always weaved using one-ply yarn with weak S-like twists. Under microscope, fiber is thick and short, and more matured fibers exist. The fibers have kinds of shape such as natural twist, helix with corner; Some fibers are judged as pure cotton texture without twists. Before 19 century, cottons planted in Shandong were all short fiber Asia cotton. From this we conclude "The lion rolling ball" parcel cloth of Qing Dynasty was weaved with Asia cotton[7]. (Fig. 6, Fig. 7)

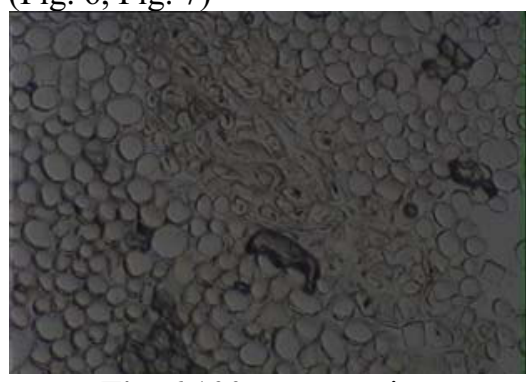

Fig. 6 100x ross section

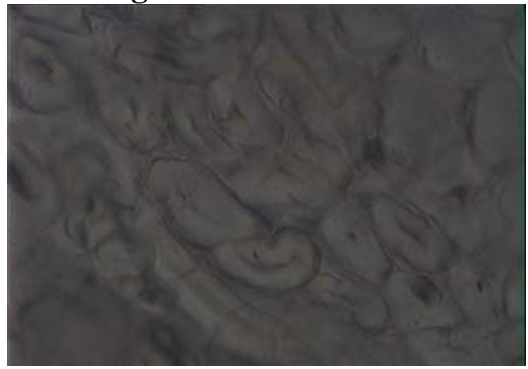

Fig. 7 400x ross section

With the help of digital 3D video fiber measure system - HZ SCOPE, the yarn trunk of "The lion rolling ball” parcel of Qing Dynasty has nearly no difference with modern Lu brocade in yarn diameter and uniformity. So we can come to a conclusion that their weaving tecnology is simlar(Fig. 8, Fig.9, Fig. 10). Detail specification is shown in Table 1. From these values we can predicate that the weaving technology is so advanced in Qing Dynasty.

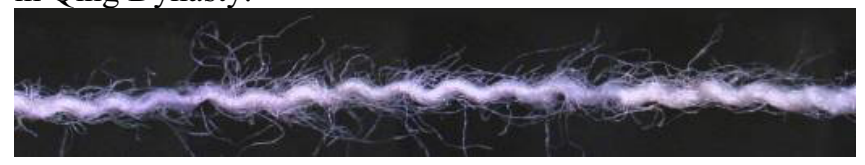

Fig. 8 the cotton of "The lion rolling ball" parcel of Qing Dynasty

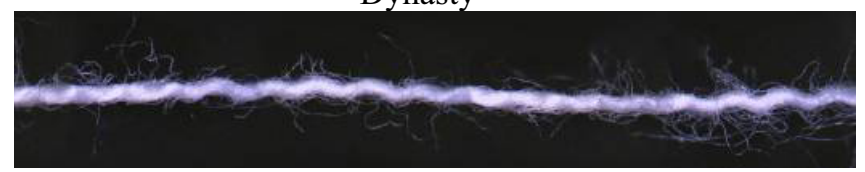

Fig. 9 modern Lu brocade

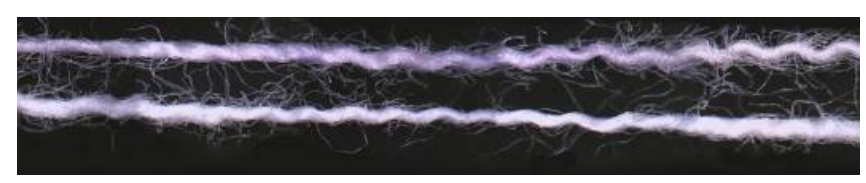

Fig. 10 the yarn comparison of "The lion rolling ball" parcel of Qing Dynasty with modern Lu brocade (by digital 3D video fiber measure system. Above is the cotton from "The lion rolling ball" parcel of Qing

Dynasty, and the under is modern Lu brocade )

Table 1. the diameter and text value of "The lion rolling ball" parcel of Qing Dynasty and modern Lu brocade

\begin{tabular}{|c|c|c|}
\hline specimens & $\begin{array}{c}\text { Yarn } \\
\text { daimeter }(\mu \mathrm{m})\end{array}$ & tex \\
\hline $\begin{array}{c}\text { "The lion rolling ball" } \\
\text { parcel of Qing Dynasty }\end{array}$ & 230 & 42.37 \\
\hline Modern Lu brocade & 220 & 41.89 \\
\hline
\end{tabular}

\section{3 analysis of the weaving technology}

Observed under microscope, "The lion rolling ball" parcel cloth of Qing Dynasty was plain woven fabrics, and the yarn thickness is not so even to indicate that it is made by spinning with manual twirling.

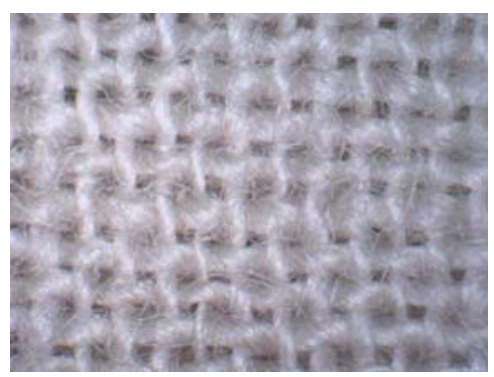




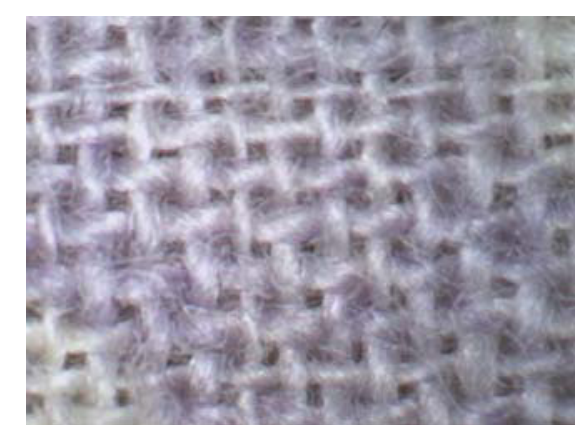

Fig. 11, Fig. 12 the yarn arrangement of "The lion rolling ball" parcel cloth of Qing Dynasty

The warp density and weft density of "The lion rolling ball" parcel cloth of Qing Dynasty are very even. Watched on the surface, Both the warp yarn and filling yarn are very straight, the warp density and weft density is very big, which warp density is $225 \mathrm{strings} / 10 \mathrm{~cm}$ and weft density is 220 strings $/ 10 \mathrm{~cm}$, and the size of parcel is $36 \mathrm{~cm}$, which is smaller than that of modern Lu brocade which is about $50 \mathrm{~cm}$ wide. So we conclude that the manual weaving technology in Shandong at the end of Qing Dynasty is not lower than the modern manual weaving technology [8].

\section{Summary}

By analyzing the material of "The lion rolling ball" parcel cloth of Qing Dynasty, the author concludes that the parcel cloth is made of ancient Asia cotton; After studying the parcel yarn by instruments, we can say that at the beginning of using cotton as weaving material, cotton weaving technology is already very mature and advanced. By analyzing the parcel pattern, the author consider that "The lion rolling ball" parcel cloth of Qing Dynasty includes rich cultural, historical and technological information, and it is one strong evidence to study ancient cotton textile.

\section{References}

1. Wenbing LI. Shandong Cotton[M] Shanghai: Shanghai Science and Technology Press, 2011, pp.1,pp.2.

2. Jie SONG, Yinnan WU, etc, Cotton Logging of LiaoCheng, Beijing: China Science and Technology Press, 1992, pp.1.

3. Zhen WANG. Nong Shu, Beijng: the Commercial Press, 09.28 of the Republic of China(1939.9).

4. Chronicle $\log$ of Shandong 18, agriculture part. Compilation committee of Shandong province. Jinan: ShangDong People's Publishing House. 2000.

5. Gu HUI.History of China silk fabric, Harbin: Heilongjiang Press, 1990, pp.148.

6. Feng ZHAO. History of silk art. Zhejiang art college Press, 1992,pp. 157.

7. Weiji CHEN.History of China textile technology, Beijng: Science Press, 1984,pp.313-315.
8. Xueling REN. The Study on Culture, Art and Textile Technology of Lu Brocade .Donghua University Press,2012,pp.135. 